\title{
External ocular pigmentation secondary to perforating eye injury
}

\author{
Mark T Benson, Ian Rennie, John Talbot
}

\begin{abstract}
The dispersal of pigment centrifugally through the conjunctiva from the site of a repaired traumatic perforation was observed. Iris tissue had been incarcerated in the wound for three days prior to surgical repair. Conjunctival biopsies were examined by light and electron microscopy. Light microscopy revealed a normal, non-pigmented conjunctival epithelium and numerous pigment-laden cells in the substantia propria. Electron microscopy showed these cells to contain melanosomes closely resembling those found in normal iris posterior pigment epithelium. The causes of abnormal external ocular pigmentation are discussed.
\end{abstract}

Pigmentation of the conjunctiva may be melanocytic or non-melanocytic in origin.

Department of

Ophthalmology, Royal

Hallamshire Hospital, Sheffield S10 2JF

M T Benson

I Rennie

J Talbot

Correspondence to:

Mr M T Benson, FRCS

Accepted for publication 2 November 1989

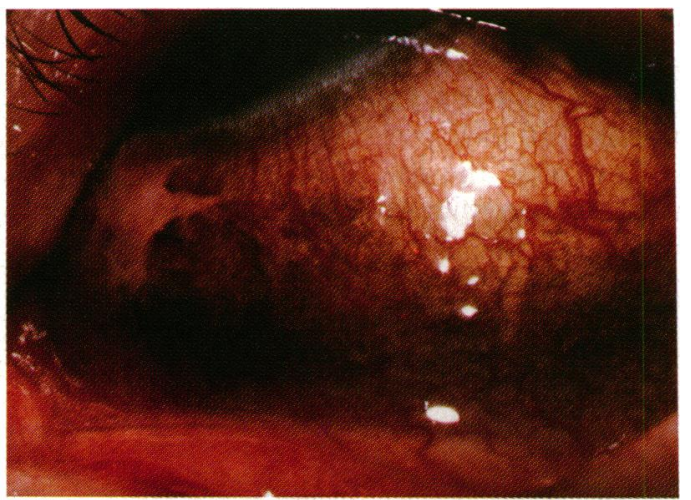

Figure 1: The patient's left inferior conjunctiva 10 weeks after the injury. There is widespread conjunctival pigmentation.
Melanocytic lesions of the conjunctiva include benign racial pigmentation, ocular melanocytosis, oculodermal melanocytosis, naevi, melanoma, and acquired melanosis. ${ }^{2}$ In the last case this may be primary acquired melanosis or secondary to a variety of conditions, including radiation, Addison's disease, pregnancy, chemical toxicity, and chronic conjunctivitis. We report here a case of acquired pigmentation of the conjunctiva and episclera related to the migration of iris pigment epithelial cells from a traumatic perforation of the globe.

\section{Case report}

A 51-year-old white male attended the Ophthalmic Emergency Department complaining of a foreign body sensation and blurred vision in his left eye. While chopping wood three days earlier he had been struck in the left eye with a piece of wood but had not sought medical attention immediately.

On examination his visual acuity was $6 / 6$ right and $6 / 36$ left. The left conjunctiva was injected and chemosed, particularly in the inferonasal quadrant. The pupil was peaked inferonasally. The anterior chamber was formed and contained moderate numbers of inflammatory cells. The right eye was normal and showed no pigmentary anomaly.

The left eye was examined under anaesthesia, and a circumferential inferonasal limbal perforation was found. Incarcerated uveal tissue was noted within the wound. The conjunctiva in the immediate vicinity of the wound was deeply pigmented. The incarcerated uveal tissue was

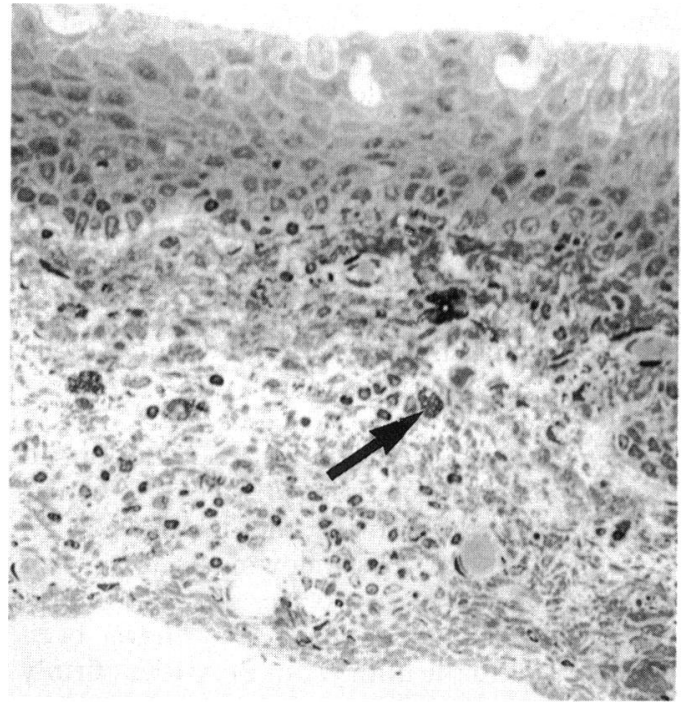

Figure 2: Conjunctival biopsy examined by light microscopy. There are numerous pigment-laden cells (arrowed) in the substantia propria. $(\times 210)$.

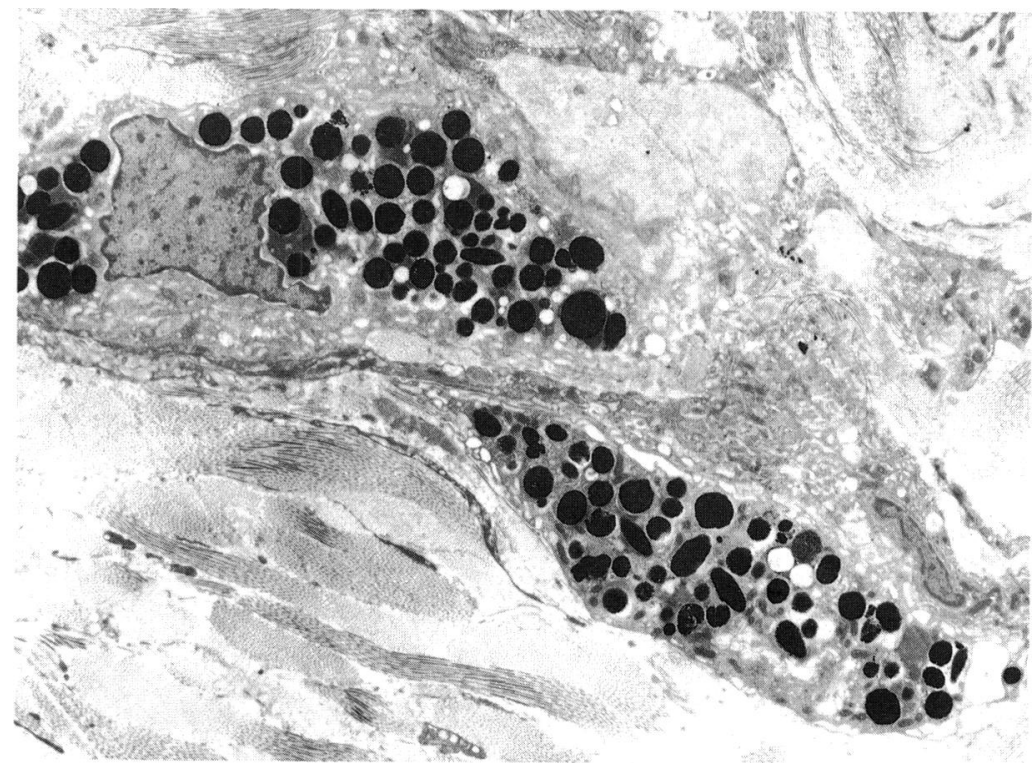

Figure 3: Electron micrograph showing pigment-laden cells in the substantia propria. $(\times 3900)$. 


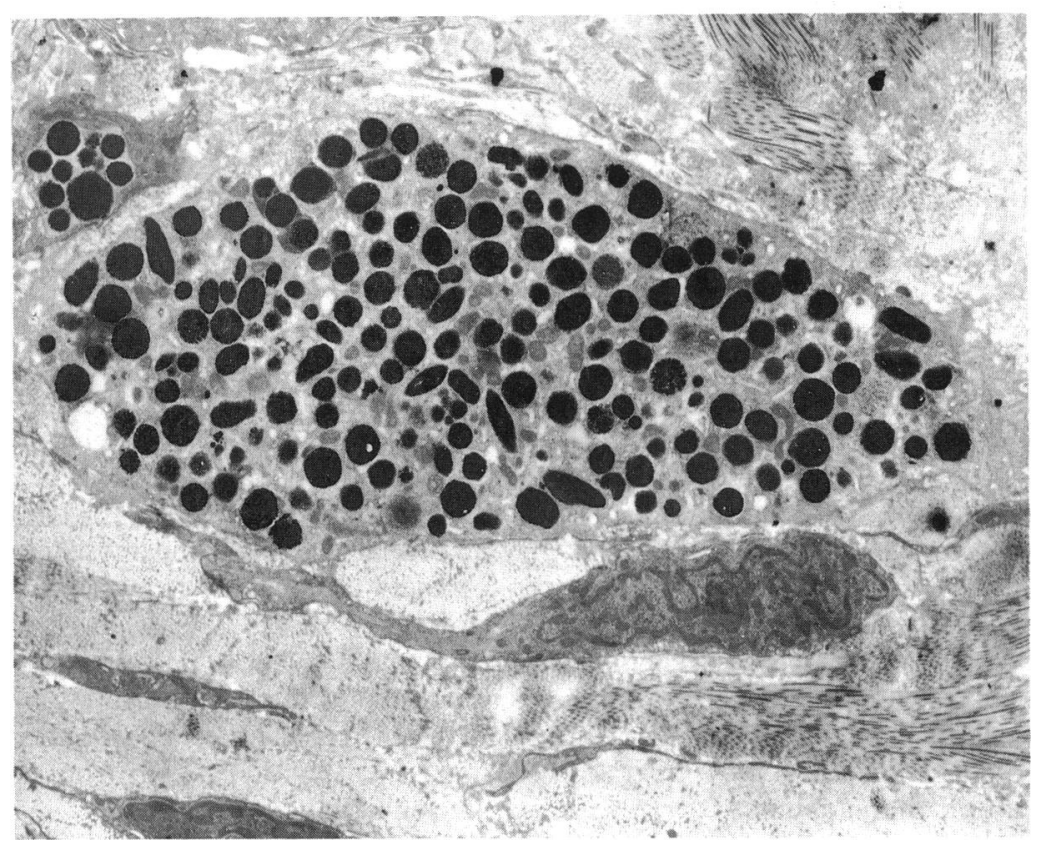

Figure 4: Electron micrograph showing cell containing melanosomes at various stages of development. $(\times 5000)$.

excised, and the wound was repaired with three $8 / 0$ virgin silk sutures. The conjunctiva was repaired with $8 / 0$ Vicryl, and subconjunctival injections of gentamicin and mydricaine were given.

Postoperatively the patient made a satisfactory recovery and was discharged five days later on a combination of topical antibiotics, steroids, and a mydriatic. He was re-examined 10 days postoperatively, when it was noted that the conjunctival pigmentation was no longer confined to the immediate vicinity of the wound but was distributed throughout the inferior conjunctiva and fornix. Ten weeks after the injury the conjunctival pigmentation was still apparent (Fig 1). Several small biopsy specimens were

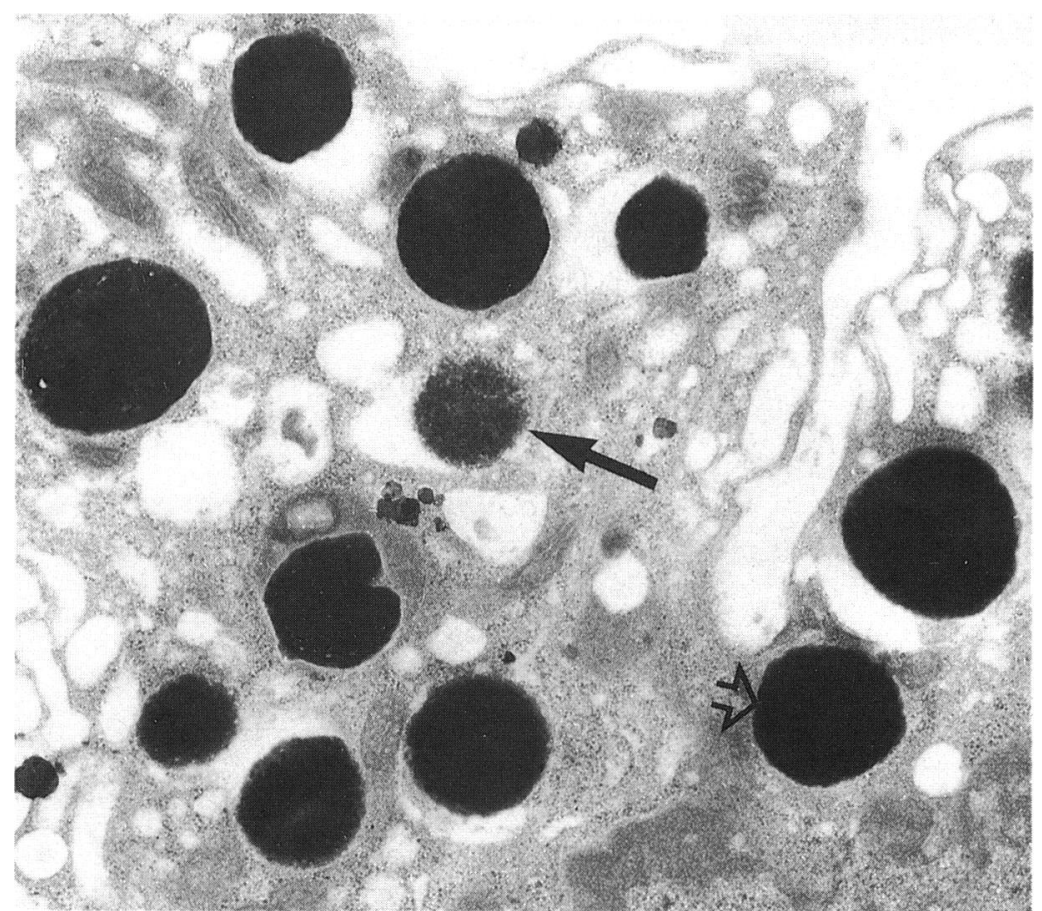

Figure 5: Electron micrograph showing stage III (partially melanised, dark arrow) and stage IV (fully melanised, light arrow) melanosomes. $(\times 20000)$. taken from the inferotemporal conjunctiva, and these were studied by light and transmission electron microscopy.

\section{METHODS}

Biopsy material for light microscopy was fixed in $10 \%$ buffered formaldehyde and processed into paraffin wax. Sections were stained with routine stains, with and without bleaching with potassium permanganate, and the Fontana method was used to test for melanin.

For electron microscopy, tissue was fixed in $3 \%$ phosphate buffered glutaraldehyde for one hour at $4^{\circ} \mathrm{C}$. The tissue was then washed in $0 \cdot 2 \%$ sucrose, postfixed in $1 \%$ osmium tetroxide for two hours at $4^{\circ} \mathrm{C}$, and dehydrated in ascending grades of alcohols and epoxypropane. The tissue was embedded in Araldite, and ultrathin $(60 \mathrm{~nm})$ sections were cut. These were stained with uranyl acetate and lead citrate and examined under a Philips 400 electron microscope.

\section{Results}

Light microscopy showed a normal nonpigmented conjunctival epithelium. Numerous pigment-laden cells were observed in the substantia propria (Fig 2). A scanty inflammatory infiltrate was also noted within the substantia propria.

Electron microscopy confirmed the presence of pigment-laden cells within the substantia propria (Fig 3). These cells contained numerous stage IV (mature) melanosomes and occasional stage III melanosomes (Figs 4 and 5). The melanosomes were round, oval, and occasionally extremely elongated, closely resembling those found in the normal iris posterior pigment epithelium (Fig 6). Occasional inflammatory cells were noted within the substantia propria.

\section{Discussion}

Abnormal external ocular pigmentation may be divided into two broad categories: congenital or early acquired type, and late acquired type. ${ }^{1}$ Melanosis oculi, oculodermal melanosis, and conjunctival naevi are examples of congenital or early acquired abnormal external ocular pigmentation. These lesions may be noted in early childhood and often show increased pigmentation at puberty or in early adult life. External ocular pigmentation acquired in later life may be benign, premalignant, or malignant. ${ }^{3-7}$ Benign acquired external ocular pigmentation may be secondary to a variety of factors, including radiation, metabolic disorders, chemical toxicity, and chronic inflammatory diseases of the conjunctiva.

The patient described in this report appears to have benign acquired external ocular pigmentation secondary to the dispersal of iris pigment epithelial cells following incarceration of the iris at the site of a perforating eye injury. Some normal pigmentation may have been present prior to the injury, but the patient firmly denied any prior ocular pigmentation, and the pigmentation appeared to disperse with time centrifugally from the perforation site, 


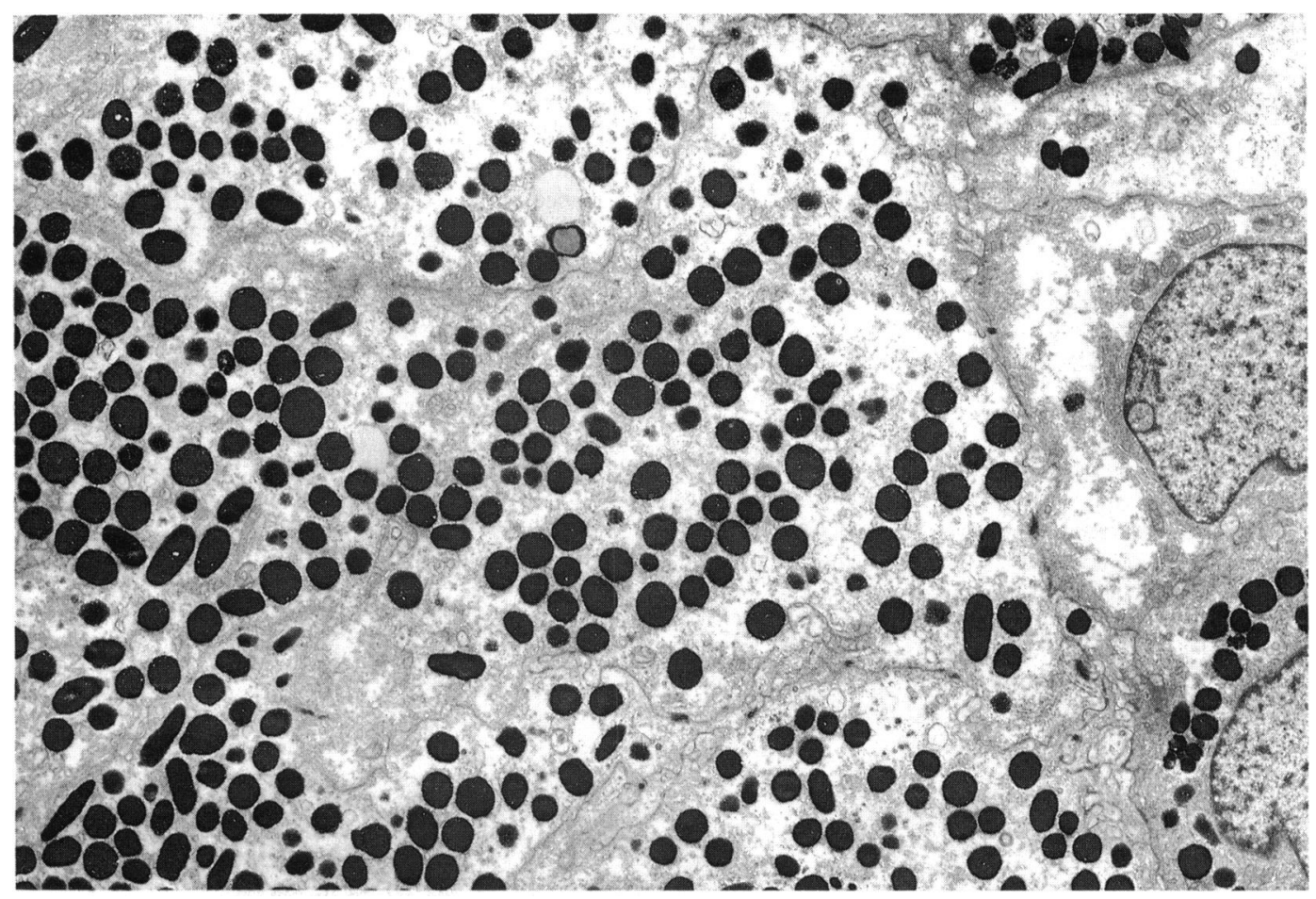

Figure 6: Electron micrograph of normal iris posterior pigmented epithelium. $(\times 3900)$.

suggesting that it was related to the injury. The shape and size of the melanosomes within the pigmented cells further support this argument. The melanosomes found in the retinal pigment epithelium and posterior pigment epithelium of the iris are in general larger than those found in skin or conjunctival epithelium. ${ }^{8}$ Indeed the morphology of these pigmented cells would seem to be similar to those of the posterior pigment epithelium of the iris (Figs 3-6).

We conclude that dispersion of pigment cells through a perforation represent another, albeit rare, cause of acquired external ocular pigmentation.
1 Henkind P, Friedman AH. External ocular pigmentation. Int Ophthalmol Clin 1971; 11: 87-111.

2 Gonder JR, Wagoner MD, Albert DM. Idiopathic acquired melanosis. Ophthalmology 1980; 87: 835-40.

3 Reese AB. Tumors of the eye. 3rd ed. Hagerstown: Harper and Row, 1976: 250-7.

4 Zimmerman LE. Criteria for management of melanosis. Arch Ophthalmol 1966; 76: 307-8.

5 Silvers DN, Jakobiec FA, Freeman TR, et al Melanoma of the conjunctiva: a clinicopathological study. In: Jackobiec FA, ed. Ocular and adnexal tumors. Birmingham, Alabama: Ocular and adnexal tumor

6 Henkind P. Conjunctival melanocytic lesions: natural history. In: Jakobiec FA, ed. Ocular and adnexal tumors. Birmingham, Alabama: Aesculapius, 1978: 572-82.

7 Folberg R, McLean IW, Zimmerman LE. Primary acquired melanosis of the conjunctiva. Hum Pathol 1985; 16: 129-35.

8 Ghadially FN. Ultrastructural pathology of the cell and matrix. 2nd ed. London: Butterworths, 1982: 599-622. 